\title{
Intoxicação de bovinos por Tetrapterys multiglandulosa (Malpighiaceae) em Mato Grosso do Sul ${ }^{1}$
}

\author{
Nilton M. Carvalho², Luiz A. Alonso ${ }^{3}$, Taila G. Cunha ${ }^{4}$, Juliana Ravedutti ${ }^{4}$, \\ Claudio S.L. Barros ${ }^{5}$ e Ricardo A.A. Lemos ${ }^{6 "}$
}

\begin{abstract}
Carvalho N.M., Alonso L.A., Cunha T.G., Ravedutti J., Barros C.S.L. \& Lemos R.A.A. 2006. [Poisoning of cattle by Tetrapterys multiglandulosa in Mato Grosso do Sul, Brazil.] Intoxicação de bovinos por Tetrapterys multiglandulosa (Malpighiaceae) em Mato Grosso do Sul. Pesquisa Veterinária Brasileira 26(3):139-146. Departamento de Medicina Veterinária, Universidade Federal de Mato Grosso do Sul, Avenida Senador Filinto Müller 2443, Caixa Postal 549, Campo Grande, MS 79070-900, Brazil. E-mail: eqrural@nin.ufms.br

Two outbreaks of poisoning by Tetrapterys multiglandulosa in cattle and the experimental reproduction of the toxicosis in sheep are described. Both outbreaks occurred on the same farm in the municipality of Bataiporã, state of Mato Grosso do Sul, Brazil. The first outbreak occurred in July-October 2004 and involved a cattle population at risk of 290 pregnant cows, which were introduced into a 60 hectare pasture with a legal reservation area heavily infested by T. multiglandulosa. Of these, 230 cows (79.3\%) aborted, had stillbirths or delivered weak calves that died few days after birth. Seven cows died, and one cow and a 10-day-old calf were necropsied. The second outbreak occurred in September-October 2005, 40 days after 285 2-year-old heifers were introduced into the same pasture infested by T. multiglandulosa and where the first outbreak had occurred in the previous year. Nine heifers got sick and died, and three of then were necropsied. Clinical signs of affected cattle, including a 10-day-old calf, were marked lethargy, loss of weight with distension of the abdomen (ascites), subcutaneous dependant edema, distended and pulsating jugular veins, dyspnea and cardiac arrhythmia. Necropsy findings included a round and dilated heart with whitish and firm areas in the myocardium, and changes related to cardiac failure such as cavitary edema, nutmeg liver, pulmonary edema, a large blood clot in the left ventricle. Histopathological changes included necrosis and fibrosis in the myocardium, chronic passive hepatic centrolobular congestion, pulmonary edema, and spongy degeneration in the white matter of the brain. Experimental sheep died 29 (Sheep 1) and 35 (Sheep 2) days after being fed average daily doses of T. multiglandulosa corresponding to $14 \mathrm{~g} / \mathrm{kg}$ (Sheep 1) and 7,5 g/kg (Sheep 2) per day. Clinical signs were observed from the 7th day (Sheep1) and the 4th day (Sheep 2) of the experiment and included tachycardia, arrhythmia, lethargy and head pressing. Necropsy and histopathologic findings in both experimental sheep were very similar to those observed in affected cattle of the two spontaneous outbreaks.
\end{abstract}

INDEX TERMS: Poisonous plants, Tetrapterys multiglandulosa, Malpighiaceae, plant poisoning, cardiomiopathy, abortion, diseases of cattle, pathology.

\footnotetext{
${ }^{1}$ Recebido em 30 de dezembro de 2005.

Aceito para publicação em 23 de janeiro de 2006 .

Parte da Dissertação de Mestrado do primeiro autor. Programa de Pós Graduação em Ciência Animal. Projeto financiado pelo Programa Institutos do Milênio, CNPq (Proc. 420012/2005-2).

2 Divisão de Clínica da Faculdade de Medicina Veterinária e Zootecnia (FMVZ), Universidade Federal de Mato Grosso do Sul (UFMS), Av. Senador Filinto Müller 2443, Cx.Postal 549, Campo Grande, MS 79070-900.
}

\footnotetext{
3 Agência Estadual de Defesa Sanitária Animal e Vegetal (Iagro), Av. Senador Filinto Müller 83, Taquarussu, MS 79765-000.

${ }^{4}$ Estagiária do Departamento de Medicina Veterinária da FMVZ, UFMS, Campo Grande, MS.

${ }^{5}$ Depto Patologia, Universidade Federal de Santa Maria, 97105-900 Santa Maria, RS.

${ }^{6}$ Depto Medicina Veterinária da FMVZ, UFMS, Campo Grande, MS. "Autor para correspondência: eqrural@nin.ufms.br
} 
RESUMO.- São descritos dois surtos da intoxicação espontânea por Tetrapterys multiglandulosa em bovinos e a reprodução experimental da toxicose em ovinos. Os dois surtos espontâneos ocorreram na mesma fazenda localizada no município de Bataiporã, Mato Grosso do Sul. O primeiro surto ocorreu em julho-outubro de 2004 e envolveu uma população bovina sob risco de 290 vacas prenhes que haviam sido introduzidas em um pasto de 60 hectares onde havia uma área de reserva legal, altamente infestada por T. multiglandulosa. Dessas, 230 vacas $(79,3 \%)$ abortaram, pariram natimortos ou bezerros fracos que morreram alguns dias após o nascimento. Sete vacas adultas morreram. Uma vaca e um bezerro de 10 dias foram necropsiados. 0 segundo surto ocorreu em setembro-outubro de 2005, 40 dias após 285 novilhas de dois anos de idade terem sido introduzidas no mesmo pasto infestado por T. multiglandulosa onde ocorrera o primeiro surto no ano anterior. Nove novilhas adoeceram e morreram; três foram necropsiadas. Os sinais clínicos dos bovinos afetados, incluindo um bezerro de 10 dias de idade, consistiam de acentuada letargia, emagrecimento com distensão do abdômen (ascite), edema subcutâneo de declive, ingurgitamento e pulso venoso da jugular, dispnéia e arritmia cardíaca. Os achados de necropsia incluíam corações globosos e com câmaras cardíacas dilatadas, áreas brancas e firmes no miocárdio e alterações relacionadas a insuficiência cardíaca como edemas cavitários, fígado de noz-moscada, edema pulmonar e grande coágulo no ventrículo esquerdo. As alterações histopatológicas incluíam necrose e fibrose do miocárdio, congestão centrolobular passiva crônica do fígado, edema pulmonar e degeneração esponjosa da substância branca do encéfalo. Os ovinos do experimento morreram 29 (Ovino 1) e 35 (Ovino 2) dias após terem recebido as folhas de T. multiglandulosa nas doses médias diárias de $14 \mathrm{~g} / \mathrm{kg}$ (Ovino 1) e 7,5 g/ $\mathrm{kg}$ (Ovino 2). 0 aparecimento dos sinais clínicos ocorreu a partir do $7^{\circ}$ dia (Ovino 1 ) e do $4^{\circ}$ dia (Ovino 2) de experimento e incluíam taquicardia e arritmia, letargia e pressão da cabeça contra objetos. Os achados de necropsia e histopatologia em ambos os ovinos experimentais foram estreitamente semelhantes aos observados nos bovinos afetados nos dois surtos espontâneos.

TERMOS DE INDEXAÇÃO: Plantas tóxicas, Tetrapterys multiglandulosa, Malpighiaceae, intoxicação por planta, miocardiopatia, aborto, doenças de bovinos, patologia.

\section{INTRODUÇÃO}

As plantas que causam insuficiência cardíaca em ruminantes são divididas em dois grandes grupos: plantas que causam insuficiência cardíaca aguda ou superaguda com morte súbita, sem lesões morfológicas apreciáveis macroscopicamente, e plantas que causam insuficiência cardíaca crônica, associada a lesões degenerativas e fibrosantes acentuadas no miocárdio, que podem ser facilmente detectadas ao exame macroscópico (Kellerman et al. 1988, Tokarnia et al. 1990, 2000, Peixoto et al. 1995).

No Brasil, são descritas três plantas do segundo grupo: Tetrapterys acutifolia, T. multiglandulosa (Tokarnia et al. 1989b, 1990, Peixoto et al. 1995) e Ateleia glazioviana (Gava \& Barros 2001, Gava et al. 2001). Na África, são relatadas várias plantas que induzem lesões miocárdicas semelhantes às do segundo grupo em bovinos: Pachystigma pygmaeum, P. thamnus, P. latifolium, Pavetta harborii,
P. schumanniana, Fadogia monticola e F. homblei (Hunter et al. 1972, Kellerman et al. 1988, Fourie et al. 1995). Embora todas as doenças desse grupo sejam caracterizadas por lesões crônicas do miocárdio, todas elas podem, com maior ou menor frequiência, causar morte súbita, o que as torna clinicamente confundíveis com as doenças causadas por plantas do primeiro grupo. Alternativamente, essas enfermidades podem estar associadas a sinais de insuficiência cardíaca congestiva (Kellerman et al. 1988, Tokarnia et al. 1990, 2000, Gava \& Barros 2001, Gava et al. 2001).

Uma outra doença cardíaca, não associada a mortes súbitas e provavelmente associada à ingestão de uma planta tóxica, ocorre em bovinos do Planalto Leste de Santa Catarina (Tokarnia et al. 1989a). A enfermidade é conhecida como "doença do peito inchado" em razão do edema subcutâneo de declive que ocorre como resultado da insuficiência cardíaca congestiva.

Os sinais clínicos de insuficiência cardíaca congestiva observado nesses casos são edema subcutâneo de declive, ingurgitamento e pulso da veia jugular. Na necropsia, observam-se edemas cavitários, fígado de noz-moscada, dilatação cardíaca e áreas brancas de contorno irregular no miocárdio, principalmente no septo interventricular. Achados histopatológicos incluem tumefação difusa de miofibras cardíacas, vacuolização de fibras isoladas e fibrose intersticial (Tokarnia et al. 2000).

Abortos também são descritos as intoxicações por T. acutifolia, T. multiglandulosa e A. glazioviana (Tokarnia et al. 1989b, Stolf et al. 1994) e na intoxicação por A. glazioviana é descrito quadro letárgico, caracterizado, principalmente, por depressão e cegueira (Gava \& Barros 2001).

Em 2004 e 2005 ocorreram surtos em bovinos de Mato Grosso do Sul, de doença caracterizada por insuficiência cardíaca congestiva, abortos e nascimento de bezerros fracos. Os objetivos deste trabalho são relatar os resultados de estudos sobre a etiologia, epidemiologia, quadro clínico e patológico da doença envolvida nesses surtos e descrever sua reprodução experimental em ovinos.

\section{MATERIAL E MÉTODOS}

Os dados epidemiológicos e clínicos foram colhidos em seis visitas à propriedade onde ocorreram os dois surtos. Essas visitas foram realizadas em outubro e dezembro de 2004 e em agosto/setembro (duas visitas) e outubro de 2005. No primeiro surto foi colhido sangue dos bovinos que abortaram para se descartar a hipótese de que os abortos tivessem ocorridos por doenças infecciosas como brucelose ou leptospirose. Foi necropsiada uma vaca nelore de 3 anos (Bov.1) com histórico de abortamento e morte após quadro clínico de insuficiência cardíaca, e um bezerro (Bov.2) que nasceu fraco e morreu aos 10 dias de idade.

Quatro novilhas de 2 anos de idade e com sinais de insuficiência cardíaca congestiva (Bovs.3-6) foram necropsiadas no segundo surto, em 2005. Foram colhidos para histopatologia o encéfalo (exceto Bov.2), coração, pulmão, fígado, rim, linfonodos mediastínicos e linfonodos mesentéricos. Esse material foi processado rotineiramente e corado por hematoxilina e eosina. Fragmentos selecionados de miocárdio foram corados pelo tricrômico de Masson para tecido conjuntivo. Material originário do exsudato encontrado na cavidade pleural e pericárdica de uma das novilhas (Bov.3) foi enviado para cultura bacteriana.

Espécimes de uma planta que existia em grande quantidade no 
pasto onde estavam os bovinos afetados e que tinha características de Tetrapterys sp, foram colhidos em 2004 e 2005 foram enviadas para identificação botânica ao Herbário HMS da Embrapa Gado de Corte de Campo Grande, MS.

As folhas dessa mesma planta foram secadas e administradas a dois ovinos (Ov.1 e 2) fêmeas prenhes com $50 \mathrm{~kg}$ cada. Esse experimento foi protocolado sob o $\mathrm{N}^{\circ}$ 79/2005 e aprovado pela Comissão de Ética no Uso de Animais, da Universidade Federal de Mato Grosso do Sul. A planta foi colhida na fase de brotação, dessecada à sombra e, posteriormente, administrada aos ovinos. Para a estimativa do peso da planta seca correspondente ao peso da planta fresca foram separadas cinco alíquotas de 100 gramas de folhas verdes; após dessecação das 5 amostras obteve-se o peso médio das amostras dessecadas e se calculou que quebra de peso entre folhas verdes e dessecadas foi de $50 \%$. Durante o experimento os dois ovinos foram mantidos em baias individuais de alvenaria, com disponibilidade de água e feno de tifton, à vontade.

O Ovino 1 consumiu um total de $10,055 \mathrm{~kg}$ de folhas da planta dessecada (correspondendo a $20,110 \mathrm{~kg}$, de folhas da planta fresca) em um período de 29 dias, equivalendo a uma dose diária (média) de $6,93 \mathrm{~g} / \mathrm{kg}$ de folha da planta dessecada correspondendo a $13,86 \mathrm{~g} / \mathrm{kg}$ de folha da planta fresca. $O$ consumo da planta não foi constante durante os 29 dias, pois quando o ovino apresentava anorexia, a administração da planta era suspensa. A planta era fornecida em doses diárias de $500 \mathrm{~g}$ de folhas dessecadas, dividida em duas doses de $250 \mathrm{~g}$ cada, uma no período da manhã, de folhas dessecadas íntegras e através de ingestão forçada e outra no período da tarde, de folhas dessecadas, moídas e misturadas em $1 \mathrm{~kg}$ de ração formulada para ovinos. Quando a mistura não era totalmente consumida, a sobra era pesada, estimandose a quantidade da planta não consumida, a qual era abatida do total fornecido, para efeito de cálculo da dose administrada.

O Ovino 2 consumiu um total de $6,44 \mathrm{~kg}$ de folhas da planta dessecada, correspondendo a $12,88 \mathrm{~kg}$ de folhas da planta fresca num período de 35 dias, equivalendo a uma dose diária (média) de $3,68 \mathrm{~g} / \mathrm{kg}$ de folhas dessecadas correspondendo a $7,36 \mathrm{~g} / \mathrm{kg}$ de folhas da planta fresca. $O$ consumo diário também não era constante e o fornecimento da planta foi interrompido nos dias em que o ovino manifestou sinais clínicos de insuficiência cardiorrespiratória, acompanhado por anorexia. Também o consumo de folhas da planta fornecida juntamente com a

Fig.1. Arbusto de Tetrapterys multiglandulosa.

Fig.2. Infrutescência de Tetrapterys multiglandulosa.

Fig.3. Edema do peito (edema subcutâneo de declive) e distensão da jugular, na intoxicação espontânea por Tetrapterys multiglandulosa (Bovino 6).

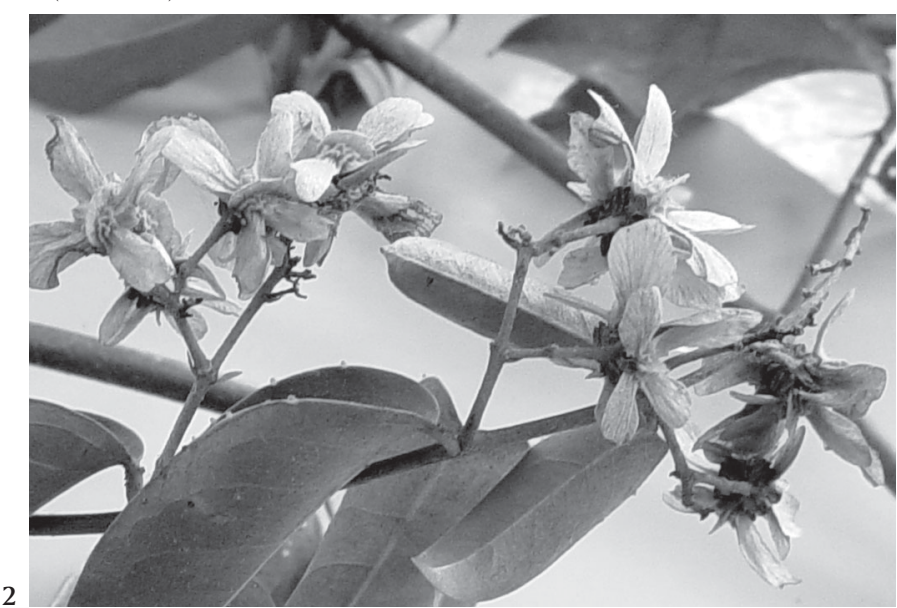

ração não foi uniforme. Para estimar a quantidade consumida foram utilizados os mesmos procedimentos descritos para o Ovino 1 . O Ovino 2 recebeu a quantidade diária de $250 \mathrm{~g}$ dividida em duas doses iguais $125 \mathrm{~g}$. Uma, por administração forçada por via oral, era feita pela manhã, consistia de folhas dessecadas íntegras; a outra, no período da tarde, consistia de folhas dessecadas, moídas e misturadas em $1 \mathrm{~kg}$ de ração formulada para ovinos. No caso do Ovino2 houve recusa na ingestão de folhas da planta fornecida com a ração e adicionou-se melado à mistura para torná-la mais palatável.

Os dois ovinos eram submetidos a exames clínicos diários para avaliação das frequiências cardíaca e respiratória, antes e após exercícios, os quais eram representados por corridas forçadas, durante 5 minutos, no interior da baia. Aspectos relacionados ao apetite e alterações do comportamento que pudessem sugerir alterações de distúrbios nervosos eram avaliados. Antes do inicio do experimento os ovinos foram everminados com albendazole e a carga parasitária foi monitorada com a contagem de OPG a cada 15 dias. Os dois ovinos foram necropsiados após morte espontânea no $29^{\circ}$ e $35^{\circ}$ dias do início do experimento. Fragmentos do encéfalo, coração, pulmão, fígado, rim e dos linfonodos mediastínicos e mesentéricos, que foram fixados em formol a $10 \%$ e processados rotineiramente para histopatologia.

\section{RESULTADOS}

\section{Casos espontâneos}

A planta presente em abundância no pasto onde ocorreram os dois surtos foi identificada como Tetrapterys multiglandulosa, da família Malpighiaceae (Fig.1 e 2).
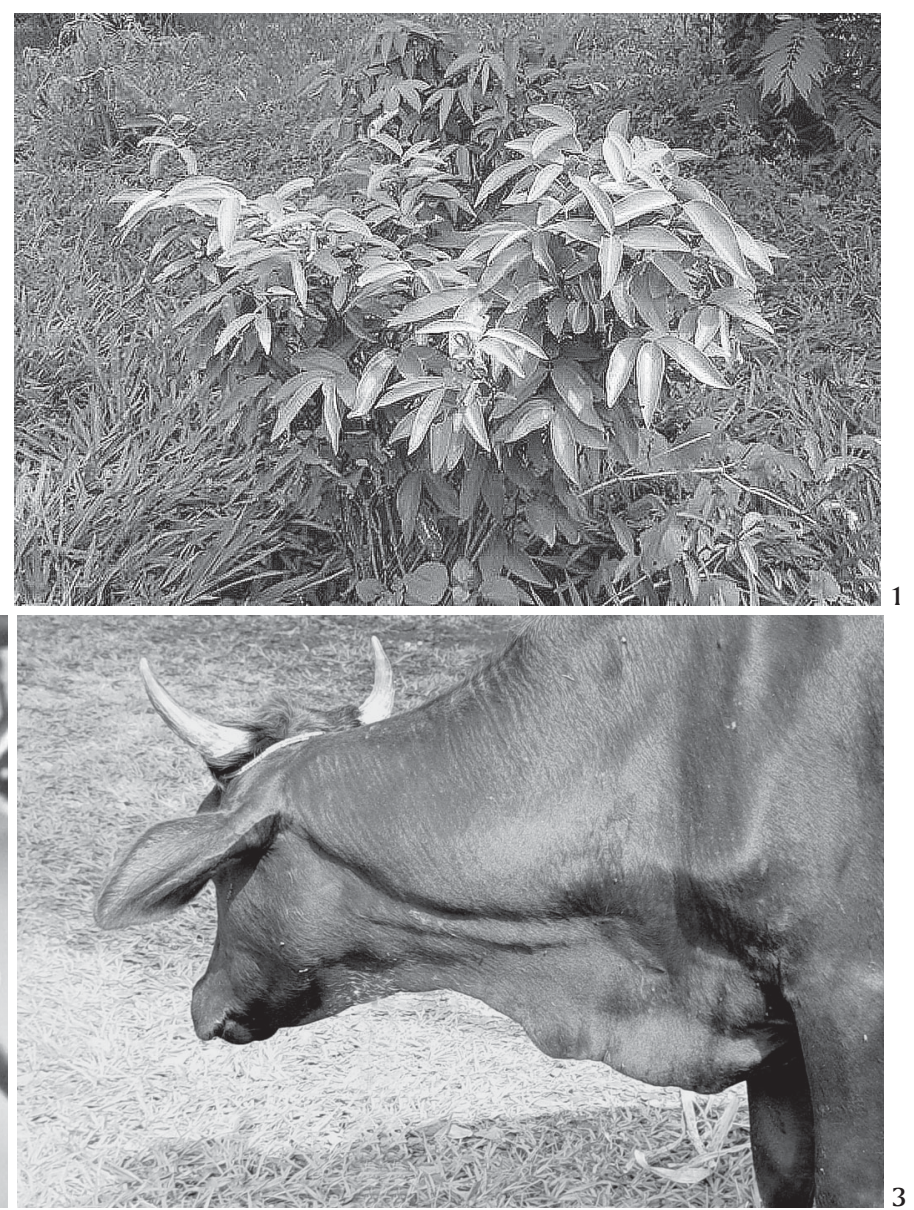
Quadro 1. Sinais clínicos de 5 bovinos intoxicados espontaneamente por Tetrapterys multiglandulosa

\begin{tabular}{|c|c|c|c|c|c|}
\hline \multirow[t]{2}{*}{ Sinal clínico } & \multicolumn{5}{|c|}{ Bovino } \\
\hline & 1 & 2 & 4 & 5 & 6 \\
\hline Edema subcutâneo ventral (de declive) & $\mathbf{a}^{\mathrm{a}}$ & $\square^{\mathrm{b}}$ & - & a & घ \\
\hline Ingurgitamento da jugular & - & $\mathbf{\square}$ & $\mathbf{\square}$ & $\mathbf{\square}$ & घ \\
\hline Pulso venoso positivo & - & - & $\square$ & $\square$ & $\square$ \\
\hline Cansaço após movimentação & $\mathbf{a}$ & $\mathbf{a}$ & $\mathbf{\square}$ & $\mathbf{\square}$ & 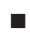 \\
\hline Letargia & $\mathbf{a}$ & - & $\mathbf{\square}$ & $\mathbf{\square}$ & 业 \\
\hline Emagrecimento & घ & घ & $\mathbf{\square}$ & $\mathbf{\square}$ & घ \\
\hline Dispnéia & $\square$ & घ & $\mathbf{\square}$ & $\mathbf{\square}$ & घ \\
\hline Aumento de volume abdominal (ascite) & घ & $\square$ & $\mathbf{\square}$ & $\square$ & $\square$ \\
\hline Arritmia cardíaca & घ & घ & - & घ & घ \\
\hline
\end{tabular}

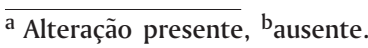

Os dois surtos espontâneos ocorreram na mesma fazenda localizada no município de Bataiporã, Estado de Mato Grosso do Sul. O primeiro surto ocorreu em julho-outubro de 2004 e envolveu uma população bovina sob risco de 290 vacas prenhes que haviam sido introduzidas em um pasto de 60 hectares, onde
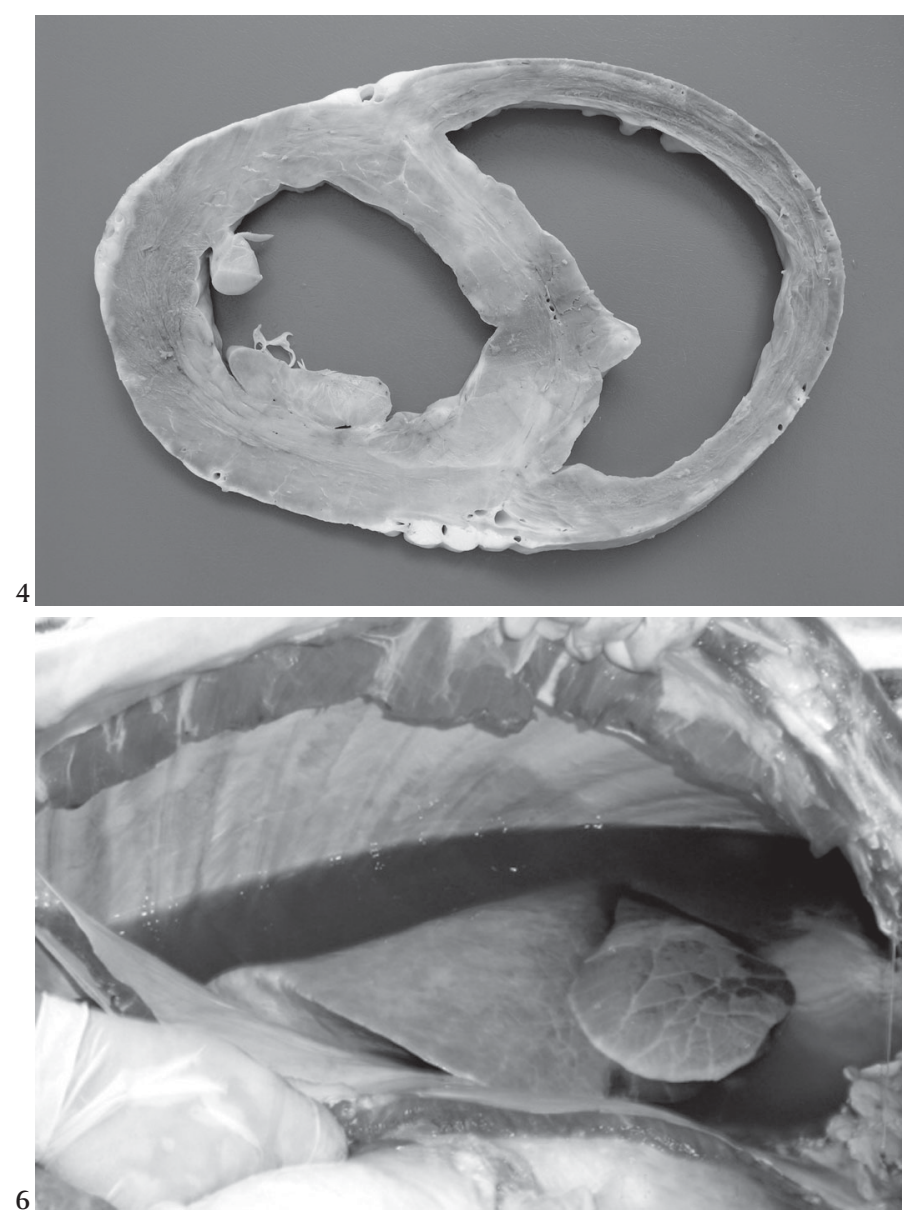

Fig.4. Áreas mais claras no miocárdio correspondem à necrose de fibras e fibrose, na intoxicação espontânea por Tetrapterys multiglandulosa (Bovino 6).

Fig.6. Hidrotórax, na intoxicação espontânea por Tetrapterys multiglandulosa (Bovino 4). havia uma área de reserva legal, altamente infestada por $T$. multiglandulosa. Dessas, 230 vacas $(79,3 \%)$ abortaram, pariram natimortos ou bezerros fracos que morreram alguns dias após 0 nascimento. Adicionalmente sete vacas adultas, que haviam abortado ou parido natimortos, morreram posteriormente.

O segundo surto ocorreu em setembro-outubro de 2005 , em 285 novilhas de 2 anos de idade que tinham sido introduzidas no mesmo pasto, onde havia a área de reserva legal infestada por T. multiglandulosa onde ocorrera o primeiro surto no ano anterior. Morreram 9 novilhas com quadro de insuficiência cardíaca, aproximadamente 30-40 dias após terem sido introduzidas na invernada. Os casos clínicos destes surtos continuaram ocorrendo, mesmo dois meses após a retirada dos bovinos do local.

Os sinais clínicos dos bovinos afetados (exceto Bov.3), incluindo um bezerro de 10 dias de idade, estão no Quadro 1. Os animais consistentemente apresentavam variados graus de edema subcutâneo nas porções ventrais do corpo (Fig.3) acentuada letargia, caracterizada por uma espécie de sonolência e fraqueza: os bovinos afetados relutavam em se mover e acabavam as-
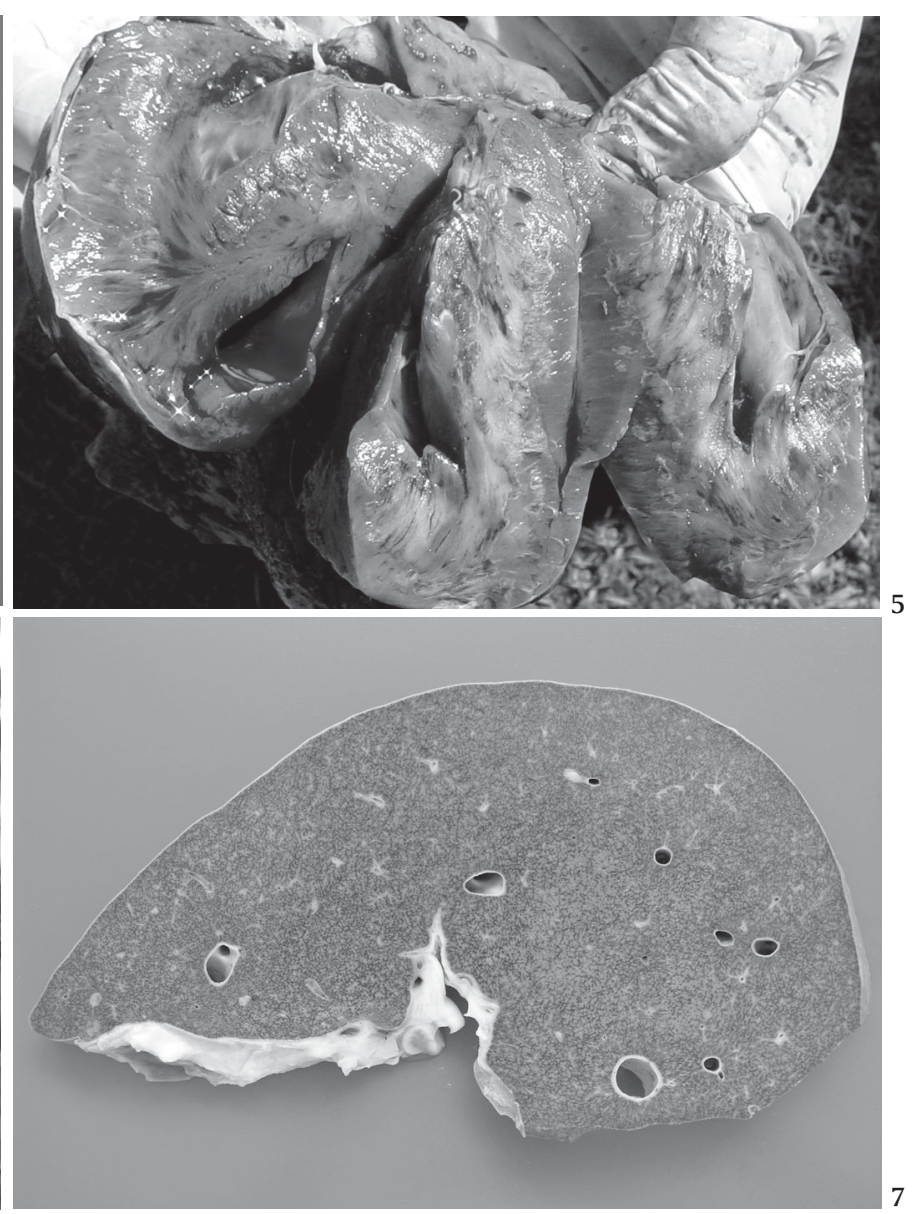

Fig.5. Áreas mais claras no miocárdio correspondem à necrose de fibras e fibrose, na intoxicação espontânea por Tetrapterys multiglandulosa (Bovino 2).

Fig.7. Fígado com aspecto de noz moscada característico de insuficiência cardíaca congestiva crônica, na intoxicação espontânea por Tetrapterys multiglandulosa (Bovino 6). 
Quadro 2. Achados de necropsia de 5 bovinos intoxicados espontaneamente por Tetrapterys multiglandulosa

\begin{tabular}{|c|c|c|c|c|c|}
\hline \multirow[t]{2}{*}{ Achados de necropsia } & \multicolumn{5}{|c|}{ Bovino } \\
\hline & 1 & 2 & 4 & 5 & 6 \\
\hline Mau estado de nutrição & $\mathbf{a}^{\mathrm{a}}$ & घ & घ & $\mathbf{\square}$ & - \\
\hline Edema subcutâneo na região ventral & - & $\square^{\mathrm{b}}$ & - & $\mathbf{\square}$ & घ \\
\hline Hidrotórax & घ & $\square$ & घ & घ & घ \\
\hline Hidropericárdio & घ & $\square$ & घ & - & घ \\
\hline Coração aumentado de volume e globoso & घ & घ & घ & - & $\mathbf{\square}$ \\
\hline Áreas branco-amareladas e firmes no miocárdio & घ & घ & घ & $\mathbf{\square}$ & घ \\
\hline Ascite & घ & $\square$ & घ & $\mathbf{\square}$ & घ \\
\hline Fígado de noz moscada & घ & घ & घ & 日 & घ \\
\hline Edema pulmonar & $\square$ & घ & घ & $\mathbf{\square}$ & $\mathbf{\square}$ \\
\hline Edema entre os músculos da coxa & $\square$ & $\square$ & - & $\square$ & $\square$ \\
\hline Edema das pregas do abomaso e do epíploon & $\square$ & $\square$ & $\square$ & $\square$ & 业 \\
\hline
\end{tabular}

$\overline{\text { aAlteração presente, }}$ bausente.

sumindo decúbito esternal com a mento apoiado ao solo. Em todos os casos havia repleção da jugular (Fig.3) e alguns bovinos mostravam distensão do abdômen e pulso venoso da jugular. Arritmia cardíaca foi observada em quase todos os casos. O Bovino 3 apresentava um grande volume (edema subcutâneo) na região esternal, que se estendia para a barbela. Na fase final da doença relutava em pastejar, apresentava respiração ofegante e cabeça baixa, mas não apresentava arritmia cardíaca. Esse bovino morreu após uma evolução de 3 meses.

Os achados de necropsia de cinco bovinos afetados estão relacionados no Quadro 2 e incluíam corações globosos e com câmaras cardíacas dilatadas, áreas brancas e firmes no miocárdio (Fig.4 e 5) e alterações relacionadas a insuficiência cardíaca como

Fig.8. O citoplasma de vários cardiomiócitos está tumefeito e eosinofílico, com núcleos picnóticos ou cariorréticos, na intoxicação espontânea por Tetrapterys multiglandulosa (Bovino 6). HE, obj.40.

Fig.9. Áreas focais de fibrose no miocárdio, na intoxicação espontânea por Tetrapterys multiglandulosa (Bovino 6). HE, obj.20.

Fig.10. Núcleos grandes, vesiculares e de contorno irregular no miocárdio, na intoxicação espontânea por Tetrapterys multiglandulosa (Bovino 6). HE, obj.40.

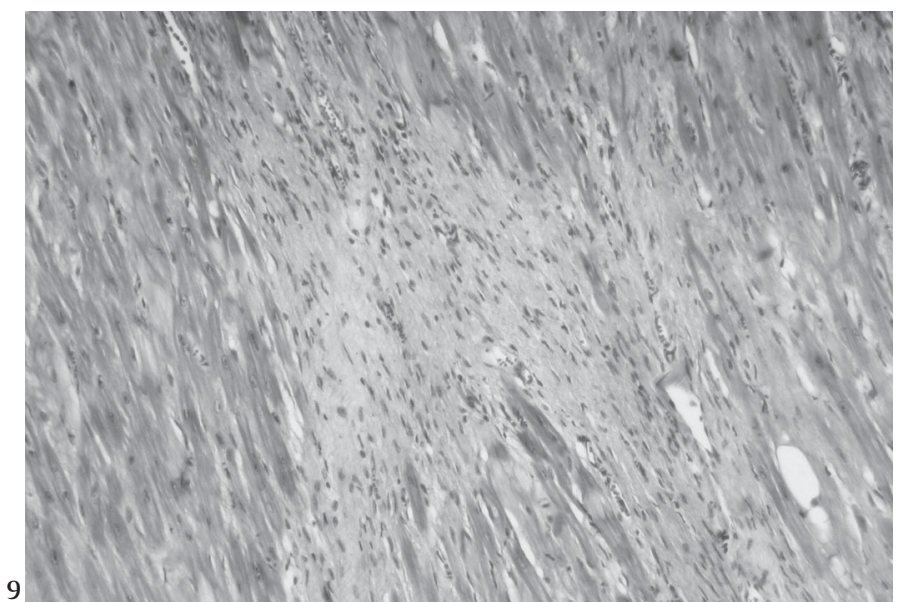

hidrotórax (Fig.6), hidropericárdio, fígado de noz-moscada (Fig.7), edema pulmonar e grande coágulo no ventrículo esquerdo. Na necropsia do Bov. 3 havia acentuado edema subcutâneo na região esternal e barbela; e aderências fibrosas entre as pleuras parietal e visceral, pericárdio e diafragma. A pleura visceral era recoberta por abundante quantidade de líquido e fibrina amarelos. O epicárdio e pericárdios estavam espessados e o saco pericárdico estava preenchido pelo mesmo exsudato encontrado na cavidade pleural. Não se observaram lesões macroscópicas no miocárdio.

As alterações histopatológicas dos bovinos afetados no surto espontâneo constam do Quadro 3. Microscopicamente, muitos cardiomiócitos tinham o citoplasma tumefeito e eosinofílico,

Quadro 3. Achados histopatológicos de 5 bovinos intoxicados espontaneamente com Tetrapterys multiglandulosa

\begin{tabular}{|c|c|c|c|c|c|}
\hline \multirow[t]{2}{*}{ Achados histopatológicos } & \multicolumn{5}{|c|}{ Bovino } \\
\hline & 1 & 2 & 4 & 5 & 6 \\
\hline Necrose de cardiomiócitos & $\mathbf{a}^{\mathrm{a}}$ & $\mathbf{\square}$ & - & - & $\mathbf{\square}$ \\
\hline Fibrose do miocárdio & $\mathbf{a}$ & $\mathbf{\square}$ & - & - & $\mathbf{\square}$ \\
\hline Cardiomiócitos com núcleo bizarro & $\square^{\mathrm{b}}$ & $\square$ & घ & $\mathbf{\square}$ & $\mathbf{a}$ \\
\hline Congestão hepática centrolobular & $\mathbf{\square}$ & घ & घ & $\mathbf{\square}$ & $\mathbf{a}$ \\
\hline Edema pulmonar & घ & $\bar{\square}$ & घ & घ & $\bar{\square}$ \\
\hline Degeneração esponjosa da substância branca encefálica & $\square$ & $\mathrm{NE}^{\mathrm{C}}$ & घ & $\square$ & घ \\
\hline
\end{tabular}

aAlteração presente; bausente; ${ }^{\mathrm{e}}$ não examinado.
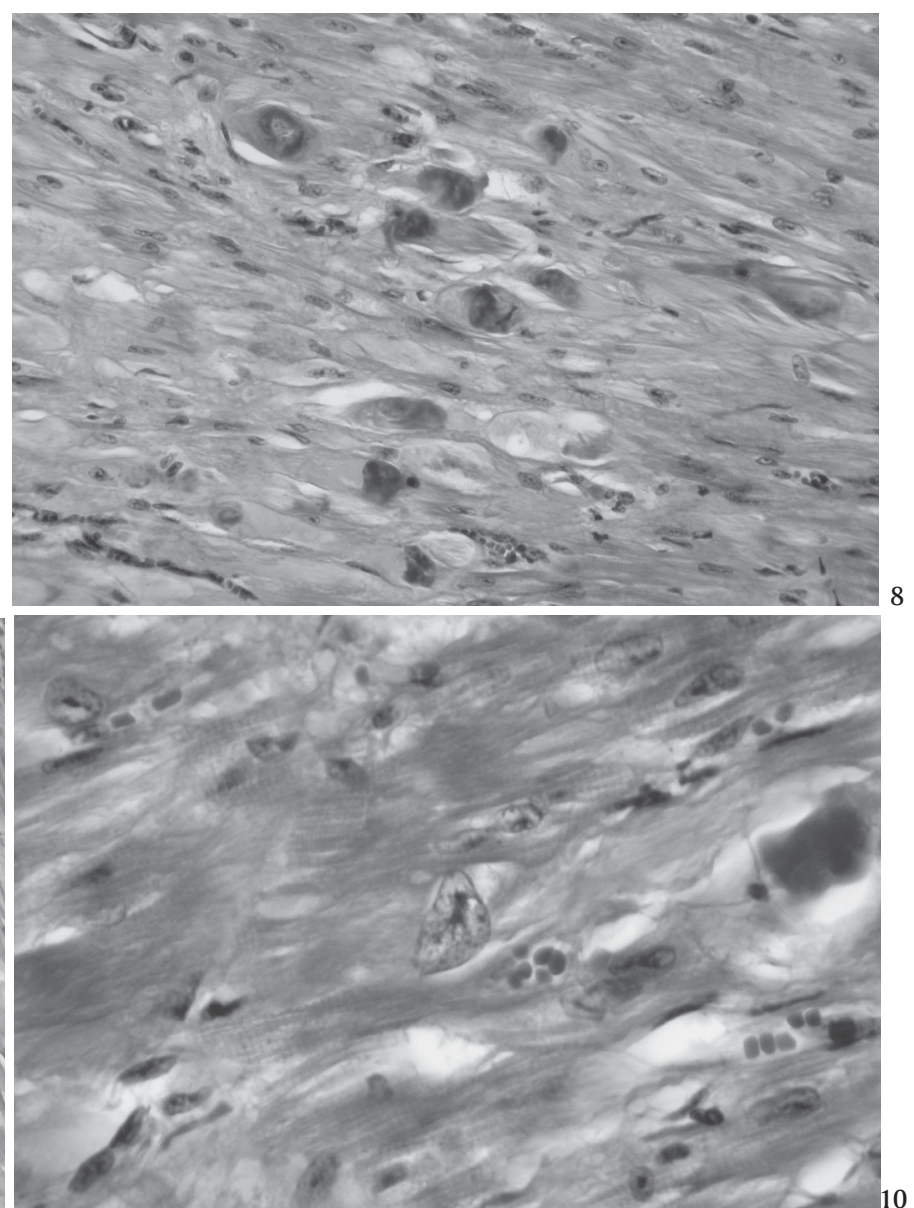
com núcleos picnóticos ou cariorréticos (Fig.8); áreas multifocais de fibrose moderada (Fig.9) ou acentuada que, às vezes, circundavam extensas áreas focais de necrose massiva consistiram de um achado constante no miocárdio. Aumento de volume e do número e alteração na forma ocorreram nos núcleos dos cardiomiócitos do Bovino 6; esses núcleos apresentavam duas a três vezes o tamanho normal, eram vesiculares, arredondados, ovais ou alongados com contornos dentados ou convolutos (Fig.10). Dois ou três núcleos, ocasionalmente mais, eram observados freqüientemente agrupados no sarcoplasma ou em fileiras. No fígado havia acentuada congestão da região centrolobular, por vezes acompanhada de fibrose. Os hepatócitos de localização mediozonal apresentavam-se vacuolizados (degeneração gordurosa). Edema pulmonar, observado em todos os casos, caracterizava-se por congestão acentuada dos capilares alveolares e preenchimento dos alvéolos por material proteináceo róseo em meio ao qual podiam ser observados macrófagos carregados de hemossiderina (células do vício cardíaco). A substância branca do encéfalo mostrava um aspecto esponjoso conferido por dilatação dos espaços periaxonais, sem tumefação axonal (status spongiosus). Essa alteração era mais pronunciada na interface da substância branca com a cinzenta.

Não havia alterações histopatológicas no coração, fígado ou encéfalo do Bovino 3. No exame bacteriológico realizado no exsudato pleural e pericárdico houve isolamento de Pasteurella sp e foi concluído que a causa da insuficiência cardíaca nesse bovino foi pericardite constritiva de origem bacteriana.

Os resultados dos exames sorológicos realizados nas vacas que abortaram foram negativos para brucelose ou leptospirose.

\section{Reprodução experimental}

O Ovino 1 consumiu um total de $10,055 \mathrm{~kg}$ de folhas da planta seca (correspondente a $20,110 \mathrm{~kg}$ de folhas da planta fresca) em um período de 29 dias, equivalendo a uma dose diária de $6,93 \mathrm{~g} / \mathrm{kg}$ de folhas da planta dessecada correspondendo a $13,86 \mathrm{~g} / \mathrm{kg}$ de folhas da planta fresca. O início dos sinais clínicos ocorreu no $7^{\circ}$ dia da ingestão de folhas de T. multiglandulosa e consistiam de arritmia cardíaca e taquicardia. No $24^{\circ}$ dia ocorreu bradicardia e dificuldade respiratória que se agravavam com o exercício. No $26^{\circ}$ dia, além dos sinais clínicos anteriormente descritos, o ovino apresentava-se apático e no $27^{\circ}$ dia mantinha a cabeça apoiada contra a parede da baia. O quadro clínico permaneceu assim por dois dias e no $29^{\circ}$ dia ocorreram acentuada bradicardia e decúbito esternal permanente. $\mathrm{O}$ animal foi encontrado em rigor mortis na manhã do dia seguinte.

O Ovino 2 consumiu um total de $6,44 \mathrm{~kg}$ de folhas da planta dessecada, correspondendo a $12,88 \mathrm{~kg}$ de folhas da planta fresca num período de 35 dias, o que corresponde a uma dose diária de $3,68 \mathrm{~g} / \mathrm{kg}$ de folhas dessecadas correspondendo a $7,36 \mathrm{~g} / \mathrm{kg}$ de folhas da planta fresca. $O$ consumo não foi constante, houve suspensão do fornecimento da planta nos dias em que o ovino manifestou sinais clínicos de insuficiência cardiorrespiratória e anorexia. O início dos sinais clínicos ocorreu a partir do $4^{\circ}$ dia da ingestão das folhas de T. multiglandulosa e consistia de arritmia cardíaca discreta, após exercícios, que perdurou até o $12^{\circ}$ dia. Do $8^{\circ}$ ao $18^{\circ}$ dias do experimento ocorreu taquicardia. No $13^{\circ}$ dia a arritmia era mais evidente e ocorria mesmo em repouso.
Entre o $14^{\circ}$ e o $18^{\circ}$ dias a arritmia voltou a ser observado somente após os exercícios e era acompanhada por dificuldade respiratória. A partir do $19^{\circ}$ dia o ovino apresentou bradicardia com arritmia até o final do experimento. No $19^{\circ}$ e $20^{\circ}$ dias o ovino continuou a apresentar arritmia acentuada, mesmo sem ser exercitado; nessa fase apareceu também pulso venoso positivo da jugular e o ovino permanecia a maior parte do tempo em decúbito esternal. Do $21^{\circ}$ ao $25^{\circ}$ dia se alimentou pouco e a administração da planta foi suspensa. O quadro clínico manteve-se inalterado até o $29^{\circ}$ dia. No $30^{\circ}$ dia acentuou-se a dificuldade respiratória e o ovino apresentava corrimento nasal mucoso, anorexia, apatia e extrema depressão, permanecendo a maior parte do tempo em decúbito esternal. No 34ํamanheceu em decúbito lateral não levantando, sendo encontrado morto na manhã do $36^{\circ}$ dia.

Os achados de necropsia foram os mesmos para os dois ovinos do experimento. Os animais eram magros e apresentavam coração de forma globosa com extensas áreas brancas e firmes visíveis tanto na superfície epicárdica como na superfície de corte. Um grande coágulo aparecia no ventrículo esquerdo. Os pulmões eram pesados e úmidos e havia abundante espuma branca na traquéia. Os fígados estavam firmes com aspecto de nozmoscada na superfície de corte. Hidrotórax e ascite, moderados no Ovino 1 e acentuados no Ovino 2, foram também observados. No útero do Ovino 1 havia um feto edematoso e no útero do Ovino 2, um feto macerado.

Microscopicamente, as lesões cardíacas e encefálicas (degeneração esponjosa) encontradas nos dois ovinos eram virtualmente idênticas às observadas nos bovinos dos casos espontâneos. Adicionalmente observaram-se edema pulmonar e congestão passiva crônica do fígado.

\section{DISCUSSÃO}

O diagnóstico da intoxicação por Tetrapterys multiglandulosa nos bovinos deste estudo foi baseado na epidemiologia, no quadro clínico, nos achados de necropsia e na histopatologia e na reprodução em dois ovinos, da doença observada nos bovinos. Ovinos já tinham sido utilizados como modelo para a reprodução da intoxicação por T. multiglandulosa (Riet-Correa et al 2005) e Ateleia glazioviana (Stigger et al. 2001, Raffi et al. 2004).

Até o momento, Tetrapterys spp eram consideradas plantas restritas à região sudeste (Tokarnia et al. 2000). Embora abortos tenham sido mencionados em relação a essa intoxicação em bovinos (Tokarnia et al. 2000), neste estudo o índice observado de abortos (e possivelmente natimortos) e recém-nascidos fracos foi extremamente alto (79,3\%). A intoxicação por Tetrapterys spp em bovinos é virtualmente idêntica à intoxicação por $A$. glazioviana nessa mesma espécie (Gava \& Barros 2001, Gava et al. 2001). Os índices de aborto observados neste estudo indicam que essas duas espécies plantas possuem o mesmo potencial abortivo.

A patogênese dos abortos causados por T. multiglandulosa foi associada a lesões placentárias (Melo et al. 2001). No entanto, Tokarnia et al (1989) nos exames histológicos de fragmentos de órgãos de um feto abortado e de um bezerro que morreu 24 horas após o nascimento, necropsiados por eles, e no exame de fragmentos de órgãos de cinco fetos abortados remetidos, veri- 
ficaram no coração e fígado as alterações histológicas mais constantes. No coração, a lesão mais conspícua foi fibrose, presente em quase todos os casos examinados (5/6). Foram verificados ainda necrose $(3 / 6)$, atrofia $(2 / 6)$, edema intracelular $(3 / 6)$ e extracelular (3/6) das fibras cardíacas. No fígado as lesões que mais chamaram a atenção foram fibrose, presente em quase todos os casos (6/7), e congestão ((4/7). Foram ainda observadas vacuolização dos hepatócitos (4/7), lise dos hepatócitos (1/7), edema do espaço de Disse (3/7) e proliferação biliar (2/7). Em fragmentos de placenta de uma vaca recebidos de fazenda onde havia problema de abortos e onde havia grande infestação dos pastos por Tetrapterys sp, verificou-se fibrose moderada a acentuada.Em um surto de intoxicação por T. multiglandulosa, Riet-Correa et al. (2005) observaram fibrose cardíaca em um bezerro de uma semana de idade que apresentava apatia, fraqueza e insuficiência respiratória. Esses dados indicam que essas lesões podem ocorrer por intoxicação transplacentária. A patogênese dos abortos na intoxicação por $A$. glazioviana foi estudado em ovinos (Raffi et al. 2004). Nessa espécie, foi demonstrado que os abortos não ocorrem por lesão na placenta, mas sim por lesões de fibrose cardíaca e status spongiosus do encéfalo, induzidas no feto por via transplacentária; fetos que sucumbem a essas lesões são expelidos do útero, aqueles afetados de forma não-letal nascem fracos e não sobrevivem. A doença observada em bezerros deste estudo e por outros autores (Tokarnia et al. 2000, Riet-Correa et al. 2005) sugere que a patogênese do aborto causado por T. multiglandulosa seja a mesma dos abortos que ocorrem na intoxicação por A. glazioviana.

A intoxicação causada por Tetrapterys spp em bovinos e ovinos é também muito semelhante à intoxicação causada Pachystigma pygmaeum, P. thamnus, P. latifolium, Pavetta harborii, P. schumanniana, Fadogia monticola e F. homblei que ocorre na África (Hunter et al. 1972, Kellerman et al. 1988, Fourie et al. 1995). Essas plantas causam uma doença caracterizada por insuficiência cardíaca aguda (morte súbita) ou, menos freqüentemente, insuficiência cardíaca congestiva crônica, mas abortos ou lesões encefálicas de status spongiosus não são relatados. Uma das características da intoxicação pelas plantas africanas é que os sinais clínicos e as lesões cardíacas ocorrem após um período de latência de 4-8 semanas após a ingestão da planta (Hunter et al. 1972, Kellerman et al. 1988, Fourie et al. 1995). Situação semelhante foi observada nos bovinos do segundo surto descrito neste trabalho, onde casos da intoxicação apareceram mesmo 2 meses após a retirada dos bovinos do pasto infestado por $T$. multiglandulosa.

Histologicamente, status spongiosus foi observado no encéfalo de quatro bovinos do surto espontâneo e dos dois ovinos intoxicados experimentalmente por T. multiglandulosa neste estudo. Lesões semelhantes já haviam sido descritas em bovinos (Tokarnia et al.1989, Gava \& Barros 2001) e ovinos (Stigger et al. 2001, Raffi et al. 2004, Riet-Correa et al. 2005) intoxicados por $A$. glazioviana e Tetrapterys spp. Essas alterações encefálicas podem ser classificadas no grupo das mielinopatias (Van der Lugt 2002) que são condições não-inflamatórias do sistema nervoso central ou periférico, nas quais o evento primário está relacionado com um distúrbio na formação, manutenção ou estabilidade da mielina e inclui várias subcategorias. A condição observada nos bovinos e ovinos deste estudo pode ser classificada na subcategoria conhecida como mielinopatia espongiforme, na qual o aspecto patológico dominante é a vacuolização sem degradação significativa ou fagocitose da mielina (Van der Lugt 2002). Quando observada na microscopia de luz, essa alteração é denominada degeneração esponjosa ou status spongiosus (Summers et al. 1995). Embora as lesões encontradas no encéfalo de bovinos intoxicados por A. glazioviana sejam morfologicamente idênticas às vistas nas encefalopatias hepáticas (Hooper 1975, Van der Lugt et al. 2002a), são provavelmente relacionadas ao efeito direto da planta sobre o sistema nervoso (Gava et al. 2001). Lesões primárias semelhantes no encéfalo são descritas na intoxicação por plantas como Helichrysum argyrosphaerum (Basson et al. 1975, Van der Lugt et al. 1996) Ornithogalum saundersiae e 0 . prasinum (Van der Lugt et al. 2002b) e na intoxicação por drogas como closantel (Ecco et al. 1999, Van der Lugt \& Venter 2002) em ovinos e caprinos.

Casos de intoxicação por Tetrapterys spp devem ser diferenciados de intoxicações causadas por outras plantas cardiotóxicas e os casos de abortos devem ser diferenciados dos abortos infecciosos. Casos superagudos da intoxicação por Tetrapterys spp, com morte súbita (Tokarnia et al. 1989b) podem ser confundidos com intoxicações com plantas aguda ou superaguda com morte súbita, sem lesões morfológicas apreciáveis macroscopicamente (Tokarnia et al. 1989b). Além disso, os casos com insuficiência cardíaca crônica devem ser diferenciados de outros casos de insuficiência cardíaca em bovinos como endocardite de tricúspide, pericardite constritiva e leucose bovina. Este aspecto do diagnóstico diferencial é bem ilustrado com o caso do Bovino 3 deste estudo. Este bovino, embora algumas das alterações clínicas (por ex., edema de peito) se assemelhassem às da intoxicação por Tetrapterys spp, não mostrou arritmia cardíaca; na necropsia e na histopatologia não se observaram lesões no miocárdio caractrísticas da intoxicação. Os achados macroscópicos no Bovino 3 e a cultura do material colhido à necropsia indicaram que neste caso tratava-se de uma pericardite constritiva bacteriana e não de lesão primária do miocárdio. 0 fato esse caso ter ocorrido em meio a um surto de intoxicação por $T$. multiglandulosa, torna o diagnóstico diferencial ainda mais importante.

Nos dois surtos estudados, a planta T. multiglandulosa mostrou uma elevada palatabilidade, pois apesar da boa disponibilidade de pastagem foi consumida avidamente pelos bovinos.

Agradecimentos.- Os autores agradecem à Escola de Qualificação Rural (Equali) da UFMS pelo apoio à realização deste trabalho.

\section{REFERÊNCIAS}

Basson P.A., Kellerman T.S., Albl P., Maltitz L.J.F., von Miller E.S. \& Welman W.G. 1975. Blindness and encephalopathy caused by Helichrysum argyrosphaerum D.C. (Compositae) in sheep and cattle. Onderstepoort J. Vet. Res. 42(4):135-148.

Ecco R., Gava A., Graça D.L. \& Barros C.S.L. 1999. Intoxicação por closantel em caprinos: relato de caso. Anais $9^{\circ}$ Encontro Nacional de Patologia Veterinária, Belo Horizonte, p.91. (Resumo)

Fourie N., Erasmus G.L., Schultz R.A. \& Prozesky L. 1995. Isolation of the toxin responsible for gousiekte, a plant-induced cardiomyopathy of ruminants in Southern Africa. Onderstepoort J. Vet. Res. 62:77-87. 
Gava A. \& Barros C.S.L. 2001. Field observations of Ateleia glazioviana poisoning in cattle in southern Brazil. Vet. Human Toxicol. 43:37-41.

Gava A., Barros C.S.L., Pilati C., Barros S.S. \& Mori A.M. 2001. Intoxicação por Ateleia glazioviana (Leg. Papilionoideae) em bovinos. Pesq. Vet. Bras. 21:49-59.

Hooper P.T. 1975. Spongy degeneration in the central nervous system of domestic animals. Part III. Occurrence and pathogenesis of hepatocerebral disease caused by hyperammonemia. Acta Neuropath. (Berl.) 31:343-351.

Hunter L.R., Naudé T.W., Adelaar T.F., Smit J.D. \& Codd L.E. 1972. Ingestion of the plant Fadogia monticula Robins as an additional cause of gousiekte in ruminants. Onderstepoort J. Vet. Res. 39 (1):71-83.

Kellerman T.S., Coetzer J.A. \& Naudé T.W. 1988. Plant Poisonings and Mycotoxicoses of Livestock in Southern Africa. Oxford University Press, Cape Town, p.83-130.

Melo M.M., Vasconcelos A.C., Dantas G.C., Serakides R. \& Alzamora Filho F. 2001. Experimental intoxication of pregnants goats with Tetrapterys multiglandulosa A.Juss. (Malpighiaceae). Arq. Bras. Med. Vet. Zootec. 53:5865.

Peixoto P.V., Loretti A.P. \& Tokarnia C.H. 1995. Doença do peito inchado, Tetrapterys spp poisoning, brisket disease and St.George disease: a comparative study. Pesq. Vet. Bras. 15:43-50.

Raffi M.B., Barros R.R., Bragança J.F.M., Rech R.R., Oliveira F.N. \& Barros C.S.L. 2004. The pathogenesis of reproductive failure induced in sheep by the ingestion of Ateleia glazioviana. Vet. Human Toxicol. 46:233238.

Riet-Correa G., Terra F.F., Schild A.L., Riet-Correa F. \& Barros S.S. 2005. Intoxicação experimental por Tetrapterys multiglandulosa (Malpighiaceae) em ovinos. Pesq. Vet. Bras. 25:91-96.

Stigger A.L., Barros C.S.L., Langohr I.M. \& Barros S.S. 2001. Intoxicação experimental por Ateleia glazioviana (Leg. Papilionoideae) em ovinos. Pesq. Vet. Bras. 21:98-108.

Stolf L., Gava A., Varaschin M.S., Neves D.S., Mondadori A.J. \& Scolari L.S. 1994. Aborto em bovinos causado pela ingestão de Ateleia glazioviana (Leg. Papilionoideae). Pesq. Vet. Bras. 14:15-18.

Summers B.A., Cummings J.F \& de Lahunta A. 1995. Degenerative diseases of the central nervous system, p.208-350. In: Ibid. (ed.) Veterinary Neuropathology. Mosby, St Louis. 527p.

Tokarnia C.H., Gava A., Peixoto P.V., Stolf L. \& Moraes S.S. 1989a. A “doença do peito inchado" (edema da região esternal) em bovinos no estado de Santa Catarina. Pesq. Vet. Bras. 9:73-83.

Tokarnia C.H., Peixoto P.V., Döbereiner J., Consorte L.B. \& Gava A. 1989b. Tetrapterys spp (Malpighiaceae), a causa de mortandades em bovinos caracterizadas por alterações cardíacas. Pesq. Vet. Bras. 9:23-44.

Tokarnia C.H., Peixoto P.V. \& Döbereiner J. 1990. Poisonous plants affecting heart function of cattle in Brazil. Pesq. Vet. Bras. 10:1-10.

Tokarnia C.H., Döbereiner J \& Peixoto P.V. 2000. Plantas Tóxicas do Brasil. Editora Helianthus, Rio de Janeiro, p.19-61.

Van der Lugt J.J. 2002. Myelinopathies, p.67. In: Van der Lugt J.J. (ed.) The Clinicopathology and Pathology of Selective Toxicoses and Storage Diseases of the Nervous System of Ruminants in Southern Africa. PhD Thesis, University of Utrecht, The Netherlands. 174p.

Van der Lugt J.J. \& Venter I. 2002. Myelin vacuolation, optic neuropathy and retinal degeneration following closantel overdosage in sheep and a goat, p.83-97. In: Van der Lugt J.J. (ed.) The Clinicopathology and Pathology of Selective Toxicoses and Storage Diseases of the Nervous System of Ruminants in Southern Africa. Tese de Doutorado, University of Utrecht, The Netherlands. 174p.

Van der Lugt J.J., Olivier J. \& Jordaan P. 1996. Status spongiosis, optic neuropathy and retinal degeneration in Helichrysum argyrosphaerum poisoning in sheep and a goat. Vet. Pathol. 33:495-502.

Van der Lugt J.J., Fourie N \& Liddel J.R. 2002a. Chronic liver disease and hepatic encephalopathy in cattle caused by Crotalaria spartioides, p.115126. In: Van der Lugt J.J. (ed.) The Clinicopathology and Pathology of Selective Toxicoses and Storage Diseases of the Nervous System of Ruminants in Southern Africa. PhD Thesis, University of Utrecht, The Netherlands. 174p.

Van der Lugt J.J., Kellerman T.S., Fourie N. \& Coetzer J.A.W. 2002b. Diarrhoea, blindness and cerebral spongy changes in cattle caused by Ornithogalum saundersiae and 0 . prasinum, p.99-114. In: Van der Lugt J.J. (ed.) The Clinicopathology and Pathology of Selective Toxicoses and Storage Diseases of the Nervous System of Ruminants in Southern Africa. Tese de Doutorado, University of Utrecht, The Netherlands. 174p. 